\title{
Correction to: Printing functional metallic 3D parts using a hybrid friction-surfacing additive manufacturing process
}

\author{
Esraa S. Abdelall ${ }^{1}$ (1) $\cdot$ Abdullah F. Al-Dwairi ${ }^{1} \cdot$ Shatha Mahmoud Al-Raba'a ${ }^{1} \cdot$ Mohamed Eldakroury $^{2}$
}

Published online: 19 June 2021

(c) Springer Nature Switzerland AG 2021

\section{Correction to: Progress in Additive Manufacturing https://doi.org/10.1007/s40964-021-00193-3}

The publication of this article unfortunately contained a mistake. Figure 10 was shown wrong. Below you can see the correct Fig. 10:

The original article has been corrected.

Publisher's Note Springer Nature remains neutral with regard to jurisdictional claims in published maps and institutional affiliations.

The original article can be found online at https://doi.org/10.1007/ s40964-021-00193-3.

Esraa S. Abdelall

abdelallesra@gmail.com

Abdullah F. Al-Dwairi

dwairy@just.edu.jo

Shatha Mahmoud Al-Raba'a

shathaarabaa@gmail.com

Mohamed Eldakroury

mdakrory@iastate.edu

1 Industrial Engineering Department, Jordan University of Science and Technology, P.O.Box 3030, Irbid 22110, Jordan

2 Department of Industrial and Manufacturing System Engineering, 3004 Black Engineering, 2529 Union Drive, Ames, IA 50011, USA 


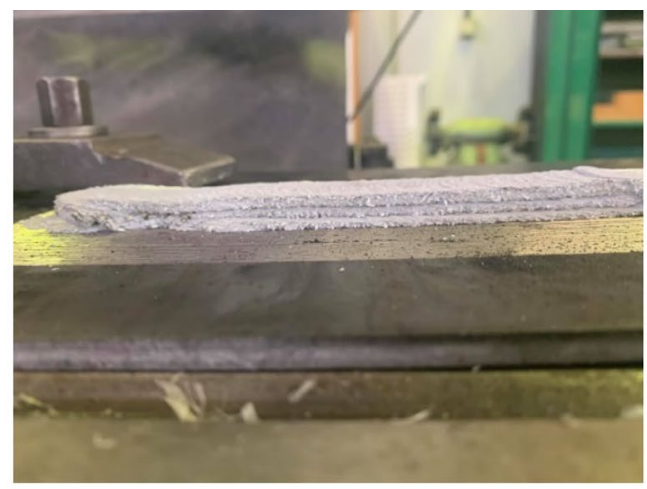

a.

External : $7.8 \mathrm{~cm} \times 1.5 \mathrm{~cm} \times 0.7 \mathrm{~cm}$

Pocket : $7.2 \mathrm{~cm} \times 1.0 \mathrm{~cm} \times 0.3 \mathrm{~cm}$

Fillets radii : $0.2 \mathrm{~mm}$
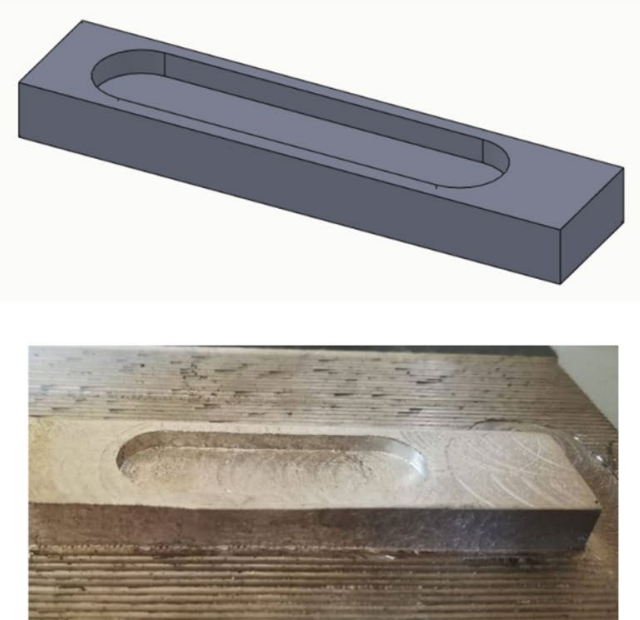

b.

Fig. 10 a Model layers deposited by HFSAM, and b final models created by the proposed HFSAM, model 1 (left), and model 2 (right)
External : $6.75 \mathrm{~cm} \times 1.5 \mathrm{~cm} \times 0.7 \mathrm{~cm}$ Pocket : $6.15 \mathrm{~cm} \times 1.0 \mathrm{~cm} \times 0.3 \mathrm{~cm}$ Boss : $5.15 \mathrm{~cm} \times 0.2 \mathrm{~cm} \times 0.3 \mathrm{~cm}$ Fillets radii : $0.2 \mathrm{~mm}$
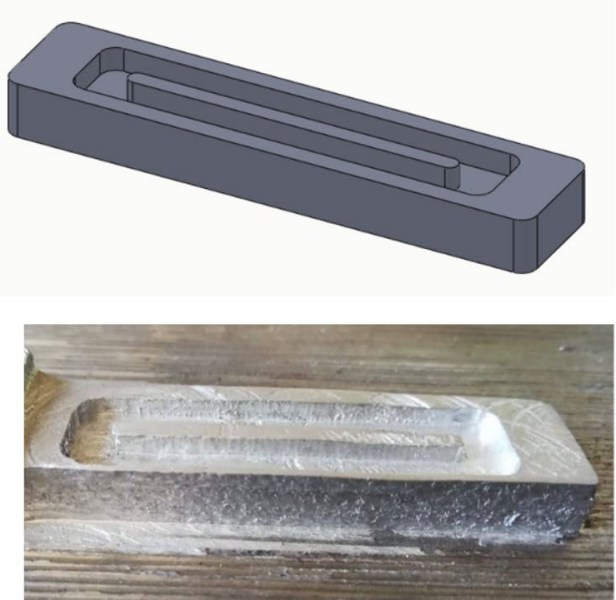